OPINION ARTICLE

\title{
The Semiglades: The Collision of Restoration, Social Values, and the Ecosystem Concept
}

\author{
Christa L. Zweig ${ }^{1,2}$ and Wiley M. Kitchens ${ }^{1}$
}

\begin{abstract}
Defining success targets in restoration and how social values affect them are two commonly discussed issues in restoration today. We believe that how success is commonly defined - with vague terms such as "healthy ecosystem" or cited as a return to a previous, historic state-needs to be reevaluated. With the increasing number of novel ecosystems, there is an increasing conflict between the ecosystem concept, social values, and restoration. This arises from the fact that ecosystems are defined by the values of the scientists describing them, necessarily constraining the ecosystem to a generally static concept. It is not directly the concept, but how it is perceived through our filter of social values that represses the creativity and innovation
\end{abstract}

needed in restoration today. Within restoration, we feel that the ecosystem concept does a disservice by ignoring the increasing number of novel systems, and that hinders real progress in a time when hesitation can be costly. To best illustrate this, we offer the example of restoration of the Florida Everglades and how it has become a novel system in pattern and process. We suggest renaming the Everglades "The Semiglades" in hopes of opening a dialog to expose social/ecosystem biases and include novel landscapes in management and planning.

Key words: Everglades, novel system, social values, success targets.

\section{Introduction}

Restoration is currently a popular topic of conversation in ecological and conservation literature (Miller \& Hobbs 2007; Seastedt et al. 2008). Two commonly discussed issues are how to define restoration success or targets and how social values affect restoration. We believe the difficulty of defining success often hinders the restoration process and needs to be addressed with innovative concepts. Success is often described as reestablishing a "healthy" ecosystem or restoring ecosystem "integrity" (Davis \& Slobodkin 2004); employing vague, value-laden terms instead of specifically defining success criteria. Recognizing how social values interact with ecological theories and ultimately affect restoration is critical and we illustrate these issues using Florida Everglades restoration. This highly politicized project is an excellent example of the collision of novel landscapes, social values, and the ecosystem concept (Fig. 1).

The concept of the ecosystem has been debated for decades, with scientists arguing over its utility as a solid ecological theory or simply as a structure to organize thoughts into a logical concept (O'Neill 2001). Within this paper, we consider the definition of an ecosystem to be "a paradigm, that is

\footnotetext{
${ }^{1}$ Florida Cooperative Fish and Wildlife Research Unit, University of Florida, Gainesville, FL

${ }^{2}$ Address correspondence to Christa L. Zweig, czweig@ufl.edu

a convenient approach to organizing thought. .. [that] takes these impossibly complex phenomena and focuses on a small subset: the average or integrated properties of all populations within a specified spatial area" (O'Neill 2001). One early criticism was the failure to include dynamics (O'Neill 2001), but the ecosystem concept has evolved over time to address this and other criticisms. However, we feel that this evolution of concept has remained largely in theory and is rarely applied in restoration. In practice, an ecosystem is defined by static, a priori assumptions (O'Neill 2001) that are often fundamentally violated in a restoration scenario, particularly when the intensity of disturbance has created a novel situation. This, coupled with an outdated, static view of ecosystems, contributes to difficulties in restoration.

The term "novel ecosystem" was first used (Chapin \& Starfield 1997) to refer to the response of an ecosystem to current and future climatic events, and has been recently discussed in terms of restoration and management (Seastedt et al. 2008). A novel ecosystem is simply an assemblage of species and environmental conditions that have never before existed in a landscape, caused by climate, human activities, or stochastic events. Within this discussion and time frame, it is most helpful to limit our definition of "novel systems" to those created by anthropogenic change. Significant, novel changes to ecosystems - and thus novel landscapes - currently occur at higher rates due to the influence of humans (Lindenmayer et al. 2008). Landscapes are being moved outside their historical range as species are introduced (especially invasive exotics) or eliminated, spatial extent is reduced, nutrient cycles are 


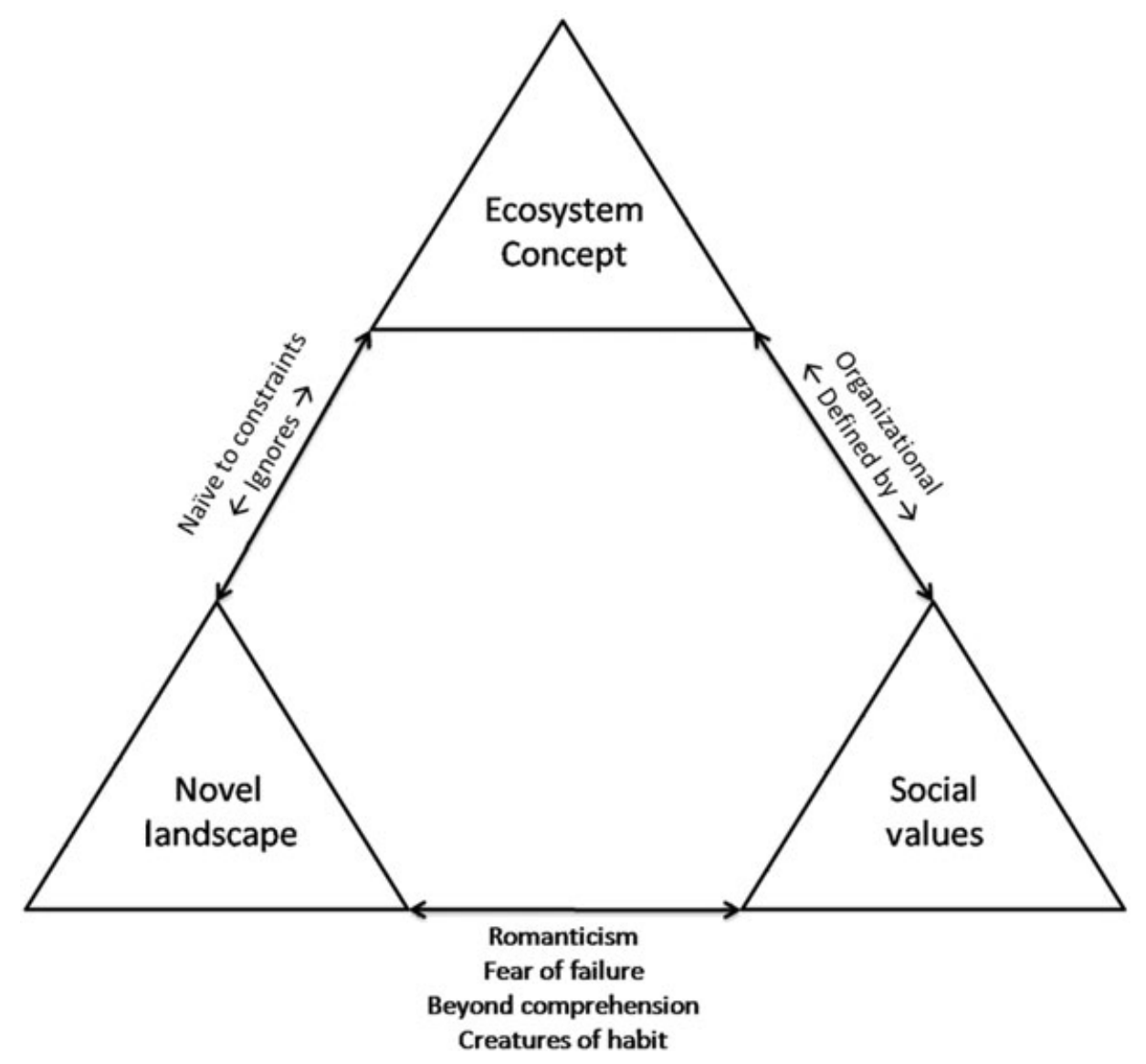

Figure 1. Interaction of the ecosystem concept, novel landscapes, and social values within ecological restoration.

enhanced or disrupted, and climate factors are altered-all creating novel situations for restoration.

The conflict between the ecosystem concept, social values, and restoration arises from the fact that ecosystems are defined by the values of the scientists describing them, necessarily constraining the ecosystem to a generally static concept. We do not argue the utility of the ecosystem concept, particularly as a method to organize infinite biotic and abiotic factors into a describable and understandable conceptual unit (O'Neill 2001). Conflict arises when that concept is perceived through our filter of social values and we repress the creativity and innovation needed in restoration today. What needs to be recognized is that the ecosystem is defined by specific assumptions - spatial, temporal, biotic, and abiotic - that have likely been violated in the current, disturbed system. It has become a novel landscape, but the recognition and acceptance of this new paradigm is often complicated by a static ecosystem concept and social values, particularly since classic restoration involves restoring functions and services to a particular period in history. Because few data are available from these previous states and there are often no reference sites available, restoration using these criteria must rely on anecdotal or "back when I was a boy" accounts, and success becomes a matter of romanticism and not science. While the ecological legacy of a site is very important information, it is easy to let ideas of the past dominate restoration. Imagining a no-analog future (Fox 2007) is very difficult, modeling it almost impossible, and describing it to managers or the public is even more complex; so working within the frame of a novel system can be quite daunting. It can also be discomforting to scientists and managers to acknowledge that the idea of restoring a system to a static, historical point (pre-human or pre-disturbance) is a flawed concept (Choi 2007), but is the first step toward practical restoration.

Novelty can be a strain on scientific/managerial resources and the way we perceive restoration, particularly dealing with the human emotions that are involved. Accepting that a system is possibly in a novel state can have immediate negative social connotations - it could imply failure in advance or even a defeatist attitude (Hobbs et al. 2006). Perhaps the novelty of the system is beyond the comprehension of those involved, or our values lead us to an ingrained, romantic perception of a former landscape that it is difficult to change within the collective subconscious. The crux is that the ecosystem concept is limited in current restoration practice because it ignores novelty and is naïve to the constraints and dynamics that allow novel landscapes to occur. Novelty cracks open the conceptual unit, which is the ecosystem, forcing it into 


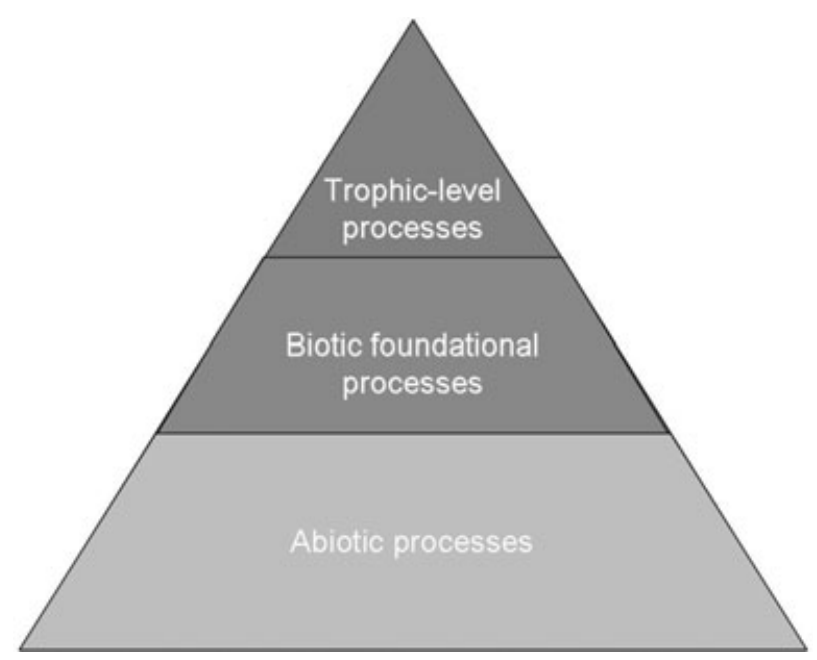

Figure 2. Hierarchy of system processes, similar to Maslow's hierarchy of needs. Using foundational processes as restoration targets adds needed simplicity when addressing novel systems.

a fluidity that betrays the basic assumptions used in its formation. Within restoration today, it is our opinion that the ecosystem concept does a disservice by ignoring the novelty of the system, and hinders real progress in a time when hesitation can be costly.

Where to start then? We feel that the increasing novelty of systems around the world emphasizes the value of simplicity in restoration. Perhaps instead of focusing on static traits from outdated ecosystem assumptions, restoration practitioners could begin with basic processes and use those as benchmarks for restoration success. Consider a system as a hierarchy of processes (Fig. 2), similar to Maslow's hierarchy of needs, with abiotic foundational processes (soil accretion, precipitation, nutrient cycles, etc.) as the base for biotic foundational (biomass, diversity, etc.) and trophic level processes (competition, predation, reproduction, etc.), each level becoming more complex.

Lower-tier processes are influenced by fewer factors and it should be, in theory, easier to understand how they are affected by novel environmental conditions and restoration actions. The key would be to determine base biotic or abiotic processes that will maximize effects on those above and include them as a suite of restoration targets within an adaptive approach that can accommodate past and future change.

\section{The Semiglades}

To best illustrate the difficulty of dealing with novel systems in restoration, we offer the example of the Florida Everglades. The pre-drainage Everglades was an area characterized by its large spatial extent (1.2 million ha), habitat heterogeneity, sheetflow, and seasonally varying hydrology (Davis et al. 1997). Draining, compartmentalization, and agriculture have reduced the spatial extent of the Everglades by $50 \%$ (Light \& Dineen 1997) and disrupted sheetflow and historical hydrology. These activities have reduced habitat heterogeneity and caused the complete disappearance of some landscape types (Sklar et al. 2005). Over $\$ 8$ billion have been promised to this restoration project and after 8 years there are still no clearly defined success criteria. A search for criteria from the official restoration plan (USACOE \& SFWMD 1999) yields the following types of targets:

- Restore ecosystem integrity.

- Restore ecosystem health.

- Restore pre-drainage ecosystem functions and processes.

These statements all reference the word "ecosystem" and are subject to the limitations of the ecosystem concept in practice and social values within the current novel landscape of the Everglades. The values are evident as all of these targets include the terms "health," "integrity," "pre-drainage," and the caveat of maintaining water supply and flood control for the south Florida urban population (Sklar et al. 2005). Some predrainage targets are in direct conflict with the social values of water supply and flood control (water timing/delivery and seepage), so reconciling the two increases the difficulty of the situation. Everglades restoration does include predictive and assessment performance measures (USACOE \& SFWMD 2004), but those are hydrologically based and rely on ecological links and benefits that may not be valid in the novel landscape (Lindig-Cisneros et al. 2003; Farina et al. 2009).

Despite the lack of specifics, are pre-drainage conditions, functions, and processes even restorable? Considering the fact that large tracts of landscape types in the pre-drainage Everglades such as cypress strands, pond apple forests, and sawgrass plains, have disappeared under agriculture and urban development (Davis et al. 1997), what will the restored characteristics, functions, and processes be? Simply restoring historic processes and hydrology to pre-drainage targets will not miraculously reverse over 100 years of human impacts. More importantly, in the absence of certain historical habitats and half of the original spatial extent, how should restoration proceed to fill these absences? Are those options sustainable?

There are many examples of how the landscape has irrevocably changed into a novel system that will not conform to historical targets. At least two, a large sawgrass plain and associated uplands on the eastern edge, have been completely eradicated. Large peat deposits throughout the northern and central Everglades formed by a vast sawgrass plain have oxidized/burned and disappeared (Sklar et al. 2002). These deposits are a key physical structure that maintained a unique and essential function of the landscape (Davis et al. 1997) by storing massive amounts of water during the wet season and releasing it as slow, overland sheetflow during the dry season. This peat was created over 3,500 years and can not be replaced within a reasonable restoration timeframe. As a substitute, the restoration has planned large reservoirs and aquifer storage/recovery wells (USACOE \& SFWMD 1999), which only provide the water storage function of the former peatland; not habitat or nutrient removal of a functioning wetland. Also, the bordering uplands on the eastern coastal ridge were an integral part of the Everglades (Davis et al. 1997), and 
provided habitat for fauna, including the vast rookeries of wading birds that were once common. Most of these areas have been converted to the megalopolis of West Palm Beach, Ft. Lauderdale, and Miami. Restoring these communities is impossible, as their presence directly conflicts with the human population of south Florida, and restoration is a non-issue. The few remaining upland remnants are also in jeopardy, threatened by further population pressures and even sea level rise (Richardson \& Frederick 1997).

Anthropogenic change and sea level rise also threaten an additional landscape type-coastal swamps. Everglades coastal communities have been degraded by restricted and diverted freshwater flows (Sklar et al. 2002), reducing their resilience and spatial extent. To compound the problem, these coastal swamps were created 3,200 YBP when sea level rise had slowed (average of $4 \mathrm{~cm} / 100$ years; Wanless et al. 1997) and conditions were appropriate for stabilization of sediments (Wanless et al. 1997). This created large areas of coastal swamps, primarily mangrove forests. Now, with accelerated sea level rise (average $20-40 \mathrm{~cm} / 100$ years; Wanless et al. 1997), the rate for sediment accumulation has been exceeded 6-10 times. Without accretion and stabilization, these coastal communities will not be restorable, even if historical freshwater flows were re-established.

There has also been a less dramatic, but no less important, degradation of other vegetation community types, including a gradual fragmentation of the characteristic ridge and slough landscape of the central Everglades. This has occurred from both overdraining and extended pooling of water along the northern and southern boundaries of water-control levees (Science Coordinating Team 2003). A degradation of the ridge/slough pattern disrupts the creation and maintenance processes of this unique subtropical patterned peatland. It is difficult to say whether there is enough intact pattern (ridges or proto-ridges; Larsen et al. 2007) to restore the area without mechanical alteration, as the exact mechanisms of formation and maintenance of the ridge and slough are not well established. More research would be helpful to understand the potential for restoration for this landscape.

Another major alteration and novel condition in the Everglades is the slow accumulation of phosphorous in the sediment, characterized by the spread of monotypic cattail (Typha spp) stands. The Everglades is an extremely oligotrophic system and even small changes in nutrient concentrations can have a large impact. Cattail is an invasive native and outcompetes sawgrass when nutrient levels are increased from agriculture runoff. Decades of agricultural activities in the Everglades watershed has left a legacy of increased phosphorous in the soil (Noe \& Childers 2007) affecting generations of vegetation communities and slowly expanding downstream.

These are well-known examples and there is widespread recognition in the scientific community that the current Everglades is quite different than the pre-drainage system (Sklar et al. 2005). What is not commonly discussed is the magnitude of the change and how that affects the landscape's response to hydrologic restoration. What will the consequences of the novel ecosystem be? Restoration of the current Everglades will likely lead to another novel state, one which we are ill-prepared to predict without careful assessment and re-evaluation of our previous assumptions of the Everglades ecosystem (Farina et al. 2009). The current and most pressing challenge for managers and scientists is to first recognize and define the novel state of the Everglades, and then accept that the pre-drainage state may not be a reasonable target for successful restoration.

\section{Conclusions}

Then how do we proceed when inaction is not an option? In order to detach old values and ideas from the Everglades ecosystem that could hinder realistic progress, and considering the spatial extent (or "ever") of the Everglades has been reduced by half, we facetiously suggest renaming it "the Semiglades" in an effort to "reboot" ideas for restoration. As major characteristics of the Everglades will never be restored within a non-geologic time frame, we feel that a readjustment of expectations is necessary and perhaps a new name would facilitate that. We present this in hopes of opening dialogs within restoration projects to expose social/ecosystem biases and include novel landscapes in management and planning.

\section{Implications for Practice}

- Acknowledging the novelty of a system helps redefine restoration targets in terms of realistic and attainable goals.

- The value of simplicity in restoration targets can not be overstated, particularly in novel systems where landscape responses to change are unpredictable.

\section{Acknowledgments}

We would like to thank Jed Redwine, Bill Pine, Tom St. Clair, Erik Powers, Brian Reichert, and Zach Welch for our conversations and their thoughtful reviews.

\section{LITERATURE CITED}

Chapin F. S., and A. M. Starfield. 1997. Time lags and novel ecosystems in response to transient climatic change in arctic Alaska. Climatic Change 35:449-461.

Choi, Y. D. 2007. Restoration ecology to the future: a call for new paradigm. Restoration Ecology 15:351-353.

Davis, S. M., L. H. Gunderson, W. A. Park, J. R. Richardson, and J. E. Mattson. 1997. Landscape dimension, composition, and function in a changing Everglades ecosystem. Pages $419-444$ in S. M. Davis and J. C. Ogden, editors. Everglades: the ecosystem and its restoration. CRC Press, Boca Raton, Florida.

Davis, M. A., and L. B. Slobodkin. 2004. The science and values of restoration ecology. Restoration Ecology 12:1-3.

Farina, J. M., B. R. Silliman, and M. D. Bertness. 2009. Can conservation biologists rely on established community structure rules to manage novel systems?. . . Not in salt marshes. Ecological Applications 19:413-422.

Fox, D. 2007. Back to the no-analog future? Science 316:823-833.

Hobbs, R. J., S. Arico, J. Aronson, J. S. Baron, P. Bridgewater, V. A. Cramer, et al. 2006. Novel ecosystems: theoretical and management aspects of the new ecological world order. Global Ecology and Biogeography 15:1-7. 
Larsen, L. G., J. W. Harvey, and J.P. Crimaldi. 2007. A delicate balance: ecohydrological feedbacks governing landscape morphology in a lotic peatland. Ecological Monographs 77:591-614.

Light, S. S., and J. W. Dineen. 1997. Water control in the Everglades: a historical perspective. Pages 47-84 in S. M. Davis and J. C. Ogden, editors. Everglades: the ecosystem and its restoration. CRC Press, Boca Raton, Florida.

Lindenmayer, D. B., J. Fischer, A. Felton, M. Crane, D. Michael, C. Macgregor, R. Montague-Drake, A. Manning, and R. J. Hobbs. 2008. Novel ecosystems resulting from landscape transformation create dilemmas for modern conservation practice. Conservation Letters 1:129-135.

Lindig-Cisneros, R., J. Desmond, K. E. Boyer, and J. B. Zedler. 2003. Wetland restoration thresholds: can a degradation transition be reversed with increased effort? Ecological Applications 13:193-205.

Miller, J. R., and R. J. Hobbs. 2007. Habitat restoration-do we know what we're doing? Restoration Ecology 15:382-390.

Noe, G. B., and D. L. Childers. 2007. Phosphorus budgets in Everglades wetland ecosystems: the effects of hydrology and nutrient enrichment. Wetlands Ecology and Management 15:189-205.

O'Neill, R. V. 2001. Is it time to bury the ecosystem concept? (With full military honors, of course!). Ecology 82:3275-3284.

Richardson, W. B., and P. C. Frederick. 1997. The faunal chapters: contexts, synthesis, and departures. Pages $709-740$ in S. M. Davis and J. C. Ogden, editors. Everglades: the ecosystem and its restoration. CRC Press, Boca Raton, Florida.

Science Coordinating Team. 2003. The role of flow in the Everglades ridge and slough landscape. Report to the South Florida Ecosystem Restoration
Task Force Working Group. http://sofia.usgs.gov/publications/papers/ sct_flows. (accessed 25 July 2009).

Seastedt, T. R., R. J. Hobbs, and K. N. Suding. 2008. Management of novel ecosystems: are novel approaches required? Frontiers in Ecology and the Environment 6:547-553.

Sklar, F. H., M. J. Chimney, S. Newman, P. McCormick, D. W. Gawlik, S. Miao, et al. 2005. The ecological-societal underpinnings of Everglades restoration. Ecological Applications 3:161-169.

Sklar, F. H., C. MCVoy, R. VanZee, D. E. Gawlik, K. Tarboton, D. Rudnick, and S. Miao. 2002. The effects of altered hydrology on the ecology of the Everglades. Pages 39-82 in J. W. Porter and K. G. Porter, editors. The Everglades, Florida Bay, and coral reefs of the Florida Keys: an ecosystem sourcebook. CRC Press, Boca Raton, Florida.

USACOE (U.S. Army Corps of Engineers) and SFWMD (South Florida Water Management District). 1999. Central and Southern Florida Project, comprehensive review study, final integrated feasibility report and programmatic environmental impact statement. http://www.evergladesplan. org/pub/restudy_eis.aspx\#mainreport. (accessed 25 July 2009).

USACOE (U.S. Army Corps of Engineers) and SFWMD (South Florida Water Management District). 2004. Program management plan for Restoration Coordination and Verification (RECOVER). September 2004 Final. http://www.evergladesplan.org/pm/recover/recover_docs/mgmt_plan/ rec_pmp_final_aug_2004.pdf. (accessed 25 July 2009).

Wanless, H. R., R. W. Parkinson, and L. P. Tedesco. 1997. Sea level control on stability of Everglades wetlands. Pages 199-2245 in S. M. Davis and J. C. Ogden, editors. Everglades: the ecosystem and its restoration. CRC Press, Boca Raton, Florida. 